\title{
Feasibility of Sewage Sludge Leached by Aspergillus Niger in Land Utilization
}

\author{
Ying $\mathrm{Xu}^{1,2 *}$, Yue-Yang Feng ${ }^{2}$ \\ ${ }^{1}$ Key Laboratory of Integrated Regulation and Resource Development on Shallow Lakes of Ministry of Education, \\ Hohai University, Nanjing, 210098, China \\ ${ }^{2}$ College of Environment, Hohai University, Nanjing, China
}

Received: 22 September 2015

Accepted: 28 November 2015

\begin{abstract}
Aspergillus niger is adopted in bioleaching to dispose of sludge from an urban wastewater treatment plant to determine the bioleaching influence of sludge on heavy metal fraction and nutritive material loss. The enrichment effect on wheat seedlings of $\mathrm{Cu}, \mathrm{Zn}, \mathrm{Pb}$, and $\mathrm{Cd}$ in sludge is researched by a soil-cultivated experiment. Results indicate that the removal rates of $\mathrm{Cu}, \mathrm{Zn}, \mathrm{Pb}$, and $\mathrm{Cd}$ are $74.1 \%, 87.6 \%, 82.1 \%$, and $97.8 \%$ in the sludge after bioleaching, respectively. The remaining heavy metal in the sludge is mainly residual fraction followed by oxidizable fraction. The bioefficiency of the heavy metal decreases significantly. The loss rates of N, P, and $\mathrm{K}$ in the sludge are $29.8 \%, 13.3 \%$, and $28.8 \%$, respectively, with good fertility after bioleaching. The enrichment capacity order of heavy metals is $\mathrm{Zn}>\mathrm{Pb}>\mathrm{Cu}>\mathrm{Cd}$ in wheat root and stem leaf, which is consistent with the order of unstable fraction content in the sludge after bioleaching.
\end{abstract}

Keywords: sludge, bioleaching, heavy metal fraction, nutritive material, heavy metal accumulation

\section{Introduction}

The popularity of wastewater treatment facilities has increased the amount of urban sludge, thus resulting in severe sludge problems. The main component of sludge is organic matter and various nutritive materials of $\mathrm{N}, \mathrm{P}$, and $\mathrm{K}$, which have good fertility. Considering disposal fees and waste resourcing, urban sludge applications in agriculture is considered a prospective disposal method of sludge. However, heavy metal in sludge is characterized by difficult immigration, easy enrichment, and extensive damage. These issues prevent the safe application of sludge in agriculture. Thus, heavy metals in sludge should be removed before conducting land applications.
The removal methods of heavy metal in sludge include chemical, bioleaching, vegetation restoration, solidification, and stabilization. Bioleaching has attracted considerable attention because of its little acid consumption, low operating cost, high removal efficiency of heavy metals, and strong practicality [1].

Bioleaching technology applies the direct effect of natural microorganisms or the indirect effect of metabolites for oxidation, reduction, complexation, adsorption, or dissolution to separate and leach insoluble components in solid phases [2, 3]. Thiobacillus ferrooxidans and T. thiooxidans are the most important autotrophic microorganisms in bioleaching technology, whereas heterotrophic microorganisms are widely applied in leaching technology. Heterotrophic leaching utilizes organic acid (i.e., citric acid, acetic acid, oxalic acid, and gluconic acid) generated by heterotrophic microorganisms

*e-mail: xyhohai@163.com 
to leach sludge. Organic acids can supply $\mathrm{H}^{+}$, and the organic radical ion can aid in the complexation of metal ions and promote metal dissolution in different fractions. In the leaching process of heavy metals in sludge, organic acids play the role of acid liquor and cheater [4]. Microorganisms can also generate exopolysaccharides, amino acids, and proteins in the process of metabolism to dissolve metals in the sludge with various mechanisms. Given that low-molecular-weight dissolved organic matter in polluted media are toxic to T. ferrooxidans and T. thiooxidans [5], heterotrophic microorganisms can employ the dissolved organic matter as a carbon and energy source for growth. Heterotrophic microorganisms have an advantage over other microorganisms in terms of repairing the sludge and soil.

Aspergillus niger is a heterotrophic microorganism that is widely applied in current bioleaching technology and has been extensively researched by local and foreign scholars. To date, bioleaching technology research is mainly related to metal removal in urban fly ash $[6,7]$, waste catalyze [8,9], and minerals [10], and is mainly engaged in the screening and optimization of bioleaching process conditions.

However, research on the leaching of heavy metals in urban sludge by $A$. niger, as well as on agricultural adaptability and environmental risks after sludge leaching, are lacking. The toxicity of heavy metals not only depends on concentration but also revolves around bioavailability [11]. The chemical fraction of heavy metals after sludge leaching has a significant impact on the environmental risks of the sludge [12]. Sludge after leaching can be used as land. The content changes of N, P, and $\mathrm{K}$ in sludge during the bioleaching process has a significant impact on sludge fertility after leaching. Hence, researching the loss of $\mathrm{N}, \mathrm{P}$, and $\mathrm{K}$ in the sludge after bioleaching is necessary. Moreover, it is also necessary to research the effect on crop growth and heavy metal accumulation in the crops of the sludge after agricultural application. For the above reasons, the current research adopts A. niger for leaching heavy metals in sludge, analyzes the main fractions of heavy metals in sludge after bioleaching, measures the loss of $\mathrm{N}, \mathrm{P}$, and $\mathrm{K}$ nutritive materials in the process of bioleaching, adopts infrared spectroscopy analysis to identify changes in the main organic functional groups in sludge after bioleaching, conducts crop growth experiment with the sludge after bioleaching, discusses the effect on crop growth and heavy metal accumulation of the sludge after agricultural application, and provides theoretical and practical references for the application of bioleaching technology in sludge treatment.

\section{Methodology}

\section{Sludge and Soil Sample}

Our sludge was sampled from a wastewater treatment plant in Nanjing City, Jiangsu Province, China.The sludge is placed in a bag after natural air drying, smashing, and grinding with a 100-mesh screen. Our soil is garden soil from Nanjing, China. The soil is placed in a bag after natural air drying, mashing, and grinding with a 100-mesh screen. The physical and chemical indexes of the sludge and soil are listed in Table 1.

\section{Culture}

A.niger is purchased from the China Center of Industrial Culture Collection (No. CICC40423) and enlarged with slant culture after purchasing. The formula of the slant culture medium is as follows: $30.0 \mathrm{~g}$ sucrose, $3.0 \mathrm{~g} \mathrm{NaNO}_{3}$, $0.5 \mathrm{~g} \mathrm{MgSO}_{4} \cdot 7 \mathrm{H}_{2} \mathrm{O}, 0.5 \mathrm{~g} \mathrm{KCl}, 0.01 \mathrm{~g} \mathrm{FeSO}_{4} \cdot 4 \mathrm{H}_{2} \mathrm{O}, 1.0 \mathrm{~g}$ $\mathrm{K}_{2} \mathrm{HPO}_{4}, 15.0 \mathrm{~g}$ agar, and $1.0 \mathrm{~L}$ distilled water. A. niger is cultured for five to seven days in a slant culture medium. Spore suspension is then prepared with sterile deionized water. The spore suspension contains $2.2 \times 10^{10}$ spores per $\mathrm{mL}$ based on the detection of dilution and spread plate method.

\section{Bioleaching Experiment}

Approximately $200 \mathrm{~mL}$ of the culture medium is added for leaching (component $(\mathrm{g} / \mathrm{L})$ : 80 sucrose, $0.5 \mathrm{~K}_{2} \mathrm{HPO}_{4}$, $4.0\left(\mathrm{NH}_{4}\right)_{2} \mathrm{SO}_{4}, 0.025 \mathrm{MgSO}_{4} \cdot 7 \mathrm{H}_{2} \mathrm{O}$, and $\left.0.05 \mathrm{KCl}\right)$ in a $500 \mathrm{~mL}$ conical flask. The conical flask is then sterilized under high-pressure steam at $120^{\circ} \mathrm{C}$ for $20 \mathrm{~min}$. The spore suspension is added after cooling with $2.0 \times 10^{8}$ inoculation amount in the leaching liquid. The microorganism is then cultured in the flask at $30^{\circ} \mathrm{C}$ in a biochemical shaker with a $120 \mathrm{r} / \mathrm{min}$ rotation speed. The flask is removed after two days and then returned to the shaker for cultivation after the addition of $2 \mathrm{~g}$ sterilized sludge.

A certain amount of supernatant is removed from the bioleaching system periodically to determine the concentrations of $\mathrm{Cu}, \mathrm{Zn}, \mathrm{Pb}$, and $\mathrm{Cd}$, as well as the content of total N, P, and K. Sludge after leaching is employed to determine the heavy metal fraction and contents of total $\mathrm{N}, \mathrm{P}$, and $\mathrm{K}$.

\section{Soil Cultivated Experiment}

Crop subject is No. 5 Yang wheat. Cultivation container is plastic container with $10 \mathrm{~cm}$ diameter and 14 $\mathrm{cm}$ height, each pot containing a $400 \mathrm{~g}$ mixture of sludge after bioleaching and soil and adding deionized water to make about $70 \%$ moisture content. The proportion of sludge and soil is $0 \%, 20 \%, 40 \%, 60 \%, 80 \%$, and $100 \%$. Firstly soak wheat seeds in deionized water for $36 \mathrm{~h}$, then select full seeds with similar sprouting, plant them in the pot, and cultivate in light incubator at $25^{\circ} \mathrm{C}$ with $12 \mathrm{~h}: 12 \mathrm{~h}$ ratio of illumination and darkness and deionized water supplemented periodically.

Observe wheat sprouting and growth condition. Each sample shall be experimented on three times. Sample only with soil is considered as control group. Wheat shall be harvested after $15 \mathrm{~d}$ of growth. After washing wheat with deionized water, stem leaf and root of the wheat are dried 
Table 1. Physical and chemical properties of the selected sludge and soil.

\begin{tabular}{|c|c|c|c|c|c|c|c|}
\hline Component & $\mathrm{Zn}$ & $\mathrm{Cd}$ & $\mathrm{Cu}$ & $\mathrm{Pb}$ & $\mathrm{TN}$ & $\mathrm{TP}$ & $\mathrm{TK}$ \\
\hline Sludge $(\mathrm{mg} / \mathrm{kg})$ & 3556.0 & 55.3 & 591.4 & 311.0 & 18105 & 15807 & 12539 \\
\hline Soil $(\mathrm{mg} / \mathrm{kg})$ & 27.9 & 0.10 & 8.51 & 6.50 & 8200 & 3100 & 1860 \\
\hline GB15618-1995* & 200 & 0.3 & 50 & 250 & - & - & - \\
\hline
\end{tabular}

*Environmental quality standards for soils (GB15618-1995) secondary standard

at $70^{\circ} \mathrm{C}$ and crushed. Heavy metal concentrations in stem leaf and root of the wheat are measured.

\section{Determination Method of the Sample}

After resolution of the sludge with acid $\left(\mathrm{HNO}_{3}+\right.$ $\mathrm{HClO}_{4}+\mathrm{HF}$ ), atomic absorption spectrometry (TAS986, Beijing Purkinje General Instrument Co., Ltd.) was employed to determine the contents of $\mathrm{Cu}, \mathrm{Zn}, \mathrm{Pb}$, and $\mathrm{Cd}$. Inductively coupled plasma-atomic emission spectrometry (Prodigy, Leeman Labs Inc., USA) was used to determine the total $\mathrm{K}$ content. After the resolution of the stem leaf and root of the wheat with acid $\left(\mathrm{HNO}_{3}+\mathrm{HClO}_{4}\right)$, atomic absorption spectrometry was employed to determine the contents of $\mathrm{Cu}, \mathrm{Zn}, \mathrm{Pb}$, and $\mathrm{Cd}$. Heavy metal fraction is determined by the BCR sequential extraction method [13]. After the resolution of the sludge and leaching liquid with potassium sulfate, UV-VIS spectrophotometry (UV-759S, Shanghai IRM Touch Inc., China) is adopted to determine the contents of total $\mathrm{N}$ and $\mathrm{P}$.

\section{Infrared Spectroscopy Analysis of the Sample}

The original sludge and experiment sludge after leaching are ground and dried, then ground mixed with dried $\mathrm{KBr}$ to an even powder. A Fourier transform infrared spectrometer (NEXUS670, Thermo Nicolet Corporation, USA) is used after the tableting process to determine the adsorption property and analyze the changes in the functional group.

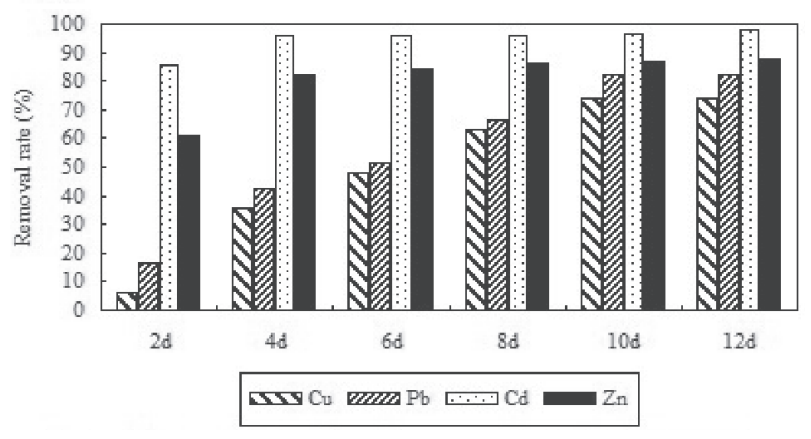

Fig. 1. Removal of various heavy metals during biolenching in time given in days.

\section{Results and Discussion}

Dissolution of Heavy Metal in the Bioleaching Process

Fig. 1 refers to the removal rate of heavy metals with time. The removal rates of $\mathrm{Zn}$ and $\mathrm{Cd}$ are $60.9 \%$ and $85.9 \%$, respectively, whereas the removal rates of $\mathrm{Cu}$ and $\mathrm{Pb}$ are only $6.2 \%$ and $16.1 \%$ after leaching for two days. The removal rate of $\mathrm{Pb}$ is $66.7 \%$ after leaching for eight days and $82.1 \%$ after leaching for 12 days. The removal rate of $\mathrm{Cu}$ is $74.1 \%$ after leaching for 12 days.

With the leaching procedure, the $\mathrm{pH}$ value of the leaching liquid progressively decreases and heavy metals are dissolved gradually. The $\mathrm{pH}$ value decreases rapidly at the initial stages of leaching. $\mathrm{Cd}$ and $\mathrm{Zn}$ are first dissolved in bulk from the sludge, whereas $\mathrm{Cu}$ and $\mathrm{Pb}$ dissolve relatively slowly. This observation is closely related to the chemical properties of organic acid salts generated from the heavy metals and metabolic products of $A$. niger.

Given that the fermentation liquid is mixed with heavy metal elements, the main fermentation products are transferred from citric acid to gluconic acid with a little oxalic acid [14]. The oxalates, citrates, and gluconates of $\mathrm{Cd}$ and $\mathrm{Zn}$ are easily soluble in water, but the oxalates of $\mathrm{Cu}$ and $\mathrm{Pb}$ are acid-soluble. Considering the relatively high $\mathrm{pH}$ value at the beginning of the leaching, the removal of $\mathrm{Zn}$ and $\mathrm{Cd}$ is considered the most significant process. The leaching liquid dissolution for heavy metals strengthens with the gradual accumulation of organic acid. The adsorption effect of metal ions for bacteria and sludge granules is weakened [15]. $\mathrm{Cu}$ and $\mathrm{Pb}$, which are difficult to remove under low acidity conditions, are eventually removed.

\section{Analysis of Heavy Metal Fraction in the Sludge} Before and after Bioleaching

Fig. 2 shows the changes in heavy metal fraction in the sludge before and after bioleaching for 12 days. The $\mathrm{Zn}, \mathrm{Cd}, \mathrm{Cu}$, and $\mathrm{Pb}$ acid-soluble/exchangeable fractions comprise $25 \%$ to $84.5 \%$ of the original sludge. Cd has the highest proportion followed by $\mathrm{Zn}$. Acid-soluble/ exchangeable fractions include heavy metals that are easily desorbed and bound to carbonate/heavy metals; both types of heavy metals can be directly absorbed by organisms, possess strong immigration abilities, and have high bioavailability. Thus acid-soluble/exchangeable 

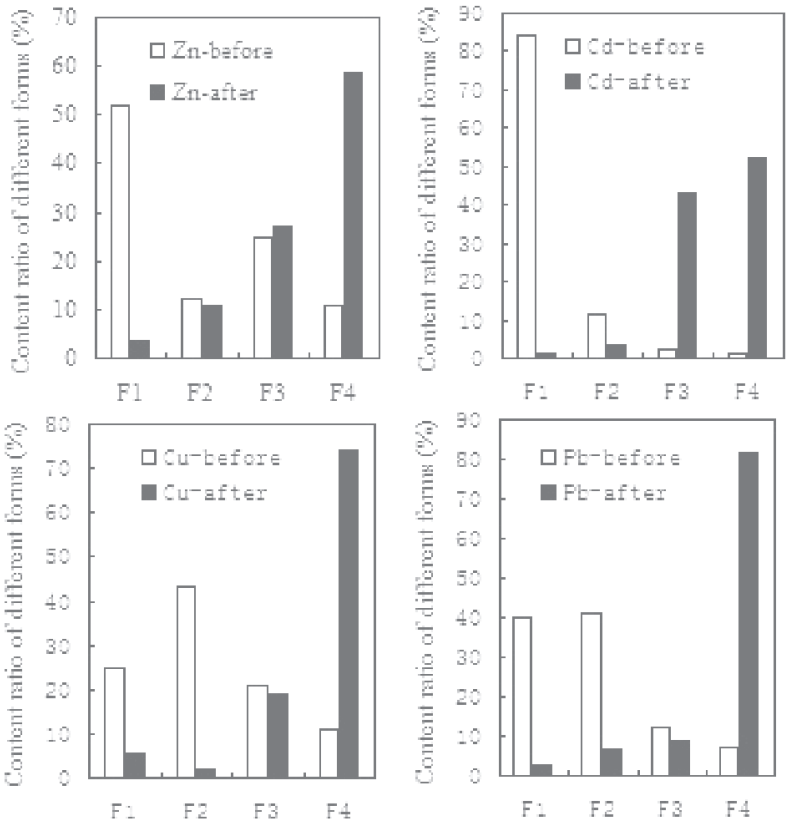

Fig. 2. Variation in partitioninh of chemical forms for heavy metals in the sludge before and after bioleaching for 12 days (F1: Acid-solublee/exchangeable fractions, F2: Reducible fractions, F3: Oxidizable fraction, F4:Residual fraction)

fractions can also be called available fractions. Heavy metal reducible fractions exist in iron and manganese oxides in adsorption and co-precipitation. The heavy metal oxidizable fraction is mainly the fraction of heavy metals bound to organics and sulfides. Both reducible and oxidizable fractions cannot be used by organisms, but some fractions can be transferred to available fractions for organism applications by changing the surrounding $\mathrm{pH}$ value and redox potential. Thus, reducible and oxidizable fractions can also be called indirect available fractions. Indirect available fractions comprise $14.2 \%$ to $64.0 \%$ of the original sludge in the following order: $\mathrm{Cu}>\mathrm{Pb}>\mathrm{Zn}>\mathrm{Cd}$. Heavy metals in residual fractions commonly exist in silicates, primary ores, and secondary ores. Such heavy metals are hardly used by organisms with the small immigration of heavy metal elements. Thus, residual fractions can also be called stable fractions. $\mathrm{Zn}, \mathrm{Cd}, \mathrm{Cu}$, and $\mathrm{Pb}$ residual fractions in the original sludge comprise only $1.3 \%$ to $11 \%$, thus resulting in the high biotoxicity of the original sludge. Experimental results indicate that the removal rates of $\mathrm{Zn}$ and $\mathrm{Cd}$ increase significantly at the beginning of leaching, whereas $\mathrm{Cu}$ and $\mathrm{Pb}$ can be removed largely but at a slow leaching rate with $A$. niger. In addition to the chemical properties of organic acid salts generated from heavy metals and the metabolic products of A. niger, another reason for the findings is related to the existing fractions of heavy metals in the sludge. $\mathrm{Zn}$ and $\mathrm{Cd}$ obtain high contents of available fractions in the original sludge; thus, such elements can be removed faster than others in the sludge. However, $\mathrm{Cu}$ and $\mathrm{Pb}$ have low contents of available fractions. The indirect available fraction is removed after transferring to the available fraction under the physiological effect of $A$. niger with increasing organic acid concentration in the leaching liquid.

Different heavy metal fractions change differently in the sludge after bioleaching with $A$. niger. After leaching with $A$. niger, over $95 \%$ and $90 \%$ of $\mathrm{Zn}, \mathrm{Cd}, \mathrm{Cu}$, and $\mathrm{Pb}$ acid-soluble/exchangeable fractions and reducible fractions, as well as $62.3 \%$ to $86.4 \%$ of oxidizable fractions, are removed from the sludge (Fig. 2). Zn and $\mathrm{Cd}$ residual fractions decrease by $30.9 \%$ and $13.9 \%$, respectively, whereas $\mathrm{Cu}$ and $\mathrm{Pb}$ residual fractions increase by 0.74 and 1.14 times, respectively. These results indicate that the $\mathrm{Cu}$ and $\mathrm{Pb}$ ions dissolved from the sludge bind to silicate minerals in the sludge. Acid-soluble/exchangeable fractions decrease by $1.0 \%$ to $5.4 \%$, whereas residual fractions increase by $52.3 \%$ to $81.7 \%$. $\mathrm{Cu}$ and $\mathrm{Pb}$ indirect available fractions also decrease significantly. Heavy metals in the sludge after leaching are mainly found in residual and oxidizable fractions. The bioavailability of heavy metals in the sludge greatly decreases, but the security of sludge land use effectively improves.

\section{Changes in the Nutritive Component of the Sludge after Bioleaching}

Heavy metals in the sludge can be removed by solidliquid separation after bioleaching; thus, changes in the $\mathrm{N}, \mathrm{P}$, and $\mathrm{K}$ contents in the sludge leaching liquid can reflect the nutritive materials lost in sludge bioleaching. $\mathrm{N}$ is an important nutritive element for plants. $\mathrm{N}$ in the sludge is mainly $\mathrm{NH}_{4}^{+}-\mathrm{N}, \mathrm{NO}_{3}^{-}-\mathrm{N} / \mathrm{NO}_{2}^{-}-\mathrm{N}$, and organic nitrogen (i.e., amino acids, cyclohexylamine, and amino compounds) [16]. Most organic nitrogen can be bound to sludge solids, whereas inorganic nitrogen can be soluble in water. In the process of bioleaching, $\mathrm{NH}_{4}{ }^{+}-\mathrm{N}$ and $\mathrm{NO}_{3}{ }^{-} \mathrm{N} /$ $\mathrm{NO}_{2}^{-}-\mathrm{N}$ absorbed on the sludge surface can be soluble in the liquid phase, thus resulting in nitrogen loss.

Phosphorus fractions existing in wastewater treatment are generally inorganic phosphorus, including calcium phosphate, iron phosphate, aluminum phosphate, and amorphous complex adsorbed on hydrate. The main phosphorus fractions in biological sludge free from chemical substances comprise organic phosphorus or polyphosphate [17]. The sludge is in an acidic environment for a long period in the process of bioleaching. Phosphorus in the sludge is converted into $\mathrm{HPO}_{4}{ }^{2-}$ and $\mathrm{H}_{2} \mathrm{PO}_{4}^{-}$, which promotes the dissolution of phosphorus in the liquid phase and results in the loss of phosphorus in the solid phase of the sludge. Potassium in the sludge may be lost during bioleaching because of the high solubility of potassium.

The concentration change of total N, P, and $\mathrm{K}$ in the leaching liquid while leaching sludge with $A$. niger are shown in Fig. 3. The initial values of total N, P, and K in the leaching liquid are derived from the culture medium for leaching. Total N, P, and $\mathrm{K}$ in the leaching liquid decrease significantly at the beginning of leaching and decrease to 401, 57, and $114 \mathrm{mg} / \mathrm{L}$ from the initial 848, 114, and 169 $\mathrm{mg} / \mathrm{L}$, respectively, on the sixth day after leaching because the nutritive component concentration becomes stable in the leaching system (Fig. 3). 

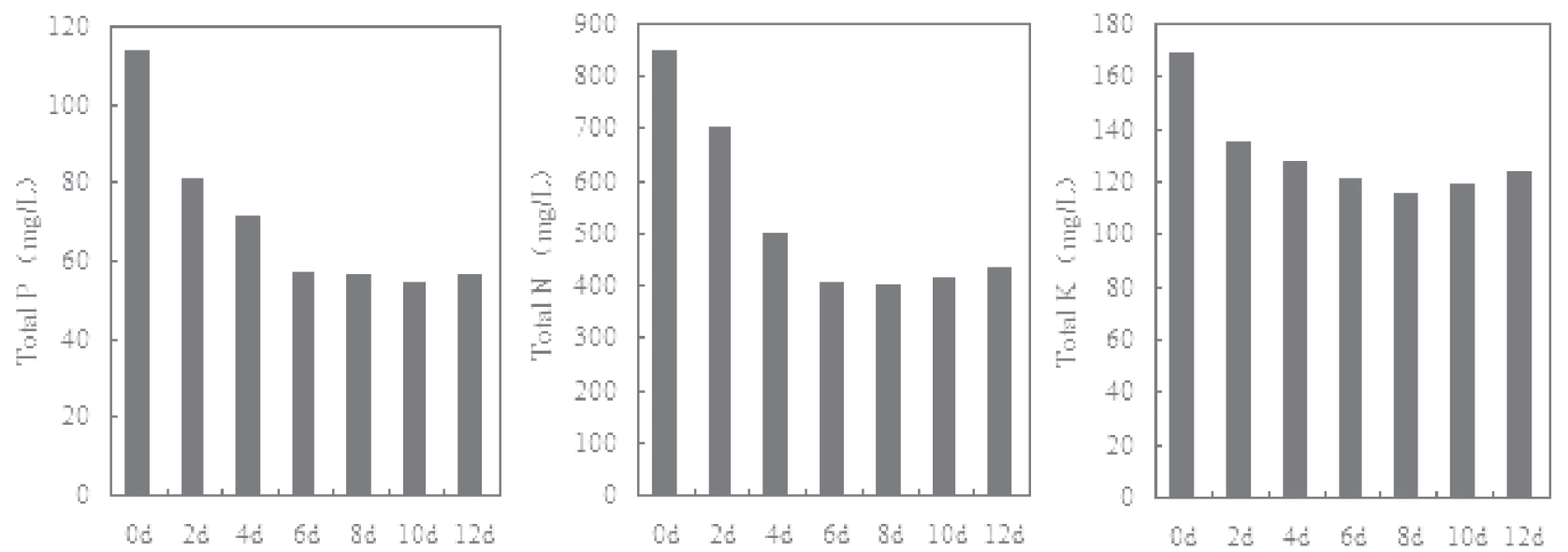

Fig. 3. Effects of bioleaching on nutritive component in sludge during the time.

On the $10^{\text {th }}$ to $12^{\text {th }}$ days after leaching with $A$. niger, the nutritive component increases slightly in the leaching liquid. The reason for the above phenomenon is that the nutritive element offered by leaching for the growth of $A$. niger is derived from the culture medium and sludge release for leaching. A. niger metabolism is accelerated at the beginning of the leaching, thus resulting in large consumption of nutritive materials. Nutritive materials released from the sludge cannot meet the growth demands of $A$. niger; thus, the concentration of total $\mathrm{N}, \mathrm{P}$, and $\mathrm{K}$ in the leaching liquid can significantly decrease. With the leaching procedure, $A$. niger metabolism becomes stable and the nutritive materials released from the sludge are balanced with the growth demands of A. niger. Hence, the concentration of nutritive materials enters into a stable stage in the leaching system. Total N, P, and K concentrations in the leaching liquid increase slightly at the later stage of leaching because the nutritive salt amounts released from the sludge surpasses the growth demands of $A$. niger, and the release of intracellular substances by A. niger in bacterial decomposition is caused by endogenous respiration. Wong et al. [18] indicates that $39 \%$ of total $\mathrm{N}$ and $45 \%$ of total $\mathrm{P}$ are lost in the sludge during the application of T. ferrooxidans in the leaching sludge at an initial $\mathrm{pH}$ value of 3.0 .

Approximately $76 \%$ of the total $\mathrm{P}$ and $38 \%$ of the total Kjeldahl $\mathrm{N}$ are lost in the sludge while applying T. thiooxidans in the leaching sludge at an initial $\mathrm{pH}$ value of 7.0. The loss rate of total N, P, and K are $29.8 \%, 13.3 \%$, and $28.8 \%$ in the sludge of this experimental research,

Table 2. The main absorbance bands in FTIR spectra and their assignments.

\begin{tabular}{|c|c|c|}
\hline Wavenumber $\left(\mathrm{cm}^{-1}\right)$ & Attribution & Compounds \\
\hline 3389,3403 & $\mathrm{OH}$ stretching vibration , $\mathrm{N}-\mathrm{H}$ stretching vibration & $\begin{array}{l}\text { Carbohydrates, Protein, Aliphatic } \\
\text { compounds }\end{array}$ \\
\hline 2923 & $\mathrm{C}-\mathrm{H}$ stretching vibration & Aliphatic compounds \\
\hline 1654 & $\mathrm{C}=\mathrm{O}$ stretching vibration, $\mathrm{C}=\mathrm{C}$ stretching vibration & Protein, Aromatic compounds \\
\hline 1543 & $\mathrm{~N}-\mathrm{H}$ variable angle vibration, $\mathrm{C}=\mathrm{C}$ stretching vibration & Protein, Aromatic compounds \\
\hline 1439 & $\begin{array}{c}\mathrm{NO}_{3}^{-} \text {Antisymmetric stretching vibration, } \mathrm{NH}_{4}^{+} \text {Asymmetry } \\
\text { variable angle vibration }\end{array}$ & Ammonium salts, Nitrate \\
\hline 1378 & $-\mathrm{CH}_{3}$ symmetrical variable angle vibration & Aliphatic compounds \\
\hline 1034 & $\begin{array}{c}\mathrm{C}-\mathrm{O}-\mathrm{C} \text { stretching vibration, } \mathrm{P}-\mathrm{O}-\mathrm{C} \text { antisymmetric stretching } \\
\text { vibration(Major is } \mathrm{C}-\mathrm{O} \text { ) }\end{array}$ & Carbohydrates, aliphatic compounds \\
\hline 807 & $\begin{array}{c}\text { P-O-C symmetrical stretching(Major is P-O), C-H Out of } \\
\text { plane bending vibration }\end{array}$ & $\begin{array}{l}\text { Aliphatic compounds, Aromatic com- } \\
\text { pounds }\end{array}$ \\
\hline 711 & $\mathrm{C}-\mathrm{H}$ out of plane bending vibration & Aromatic compounds \\
\hline 531,469 & M-O Out of plane bending vibration ( $\mathrm{M}$ refers to $\mathrm{Fe}, \mathrm{Mn}$ ) & Metallic oxide \\
\hline
\end{tabular}

The interpretations are based on data of numerous studies [19-22]. 
respectively. Compared with the loss situation of nutritive salt in the Thiobacillus leaching system, the loss rate of total P decreases significantly. This condition is mainly related to the different nutritive materials required for the growth of different microorganisms. The accumulation of organic acids in the leaching system by using $A$. niger results in a large decrease in the $\mathrm{pH}$ value of the leaching liquid and effectively restricts the release of the $\mathrm{NH}_{3}$ generated by the $\mathrm{NH}_{4}^{+}$in the aqueous solution. After the separation of solid and liquid in the leaching system, some nutritive materials in the culture medium and A. niger may be adsorbed on the surface of the sludge. A. niger is rich in nutritive elements such as $\mathrm{N}, \mathrm{P}$, and $\mathrm{K}$. Bioleaching can still meet the demands for land use even though some nutritive materials are lost in the sludge.

\section{Infrared Spectroscopy Analysis}

Infrared spectroscopy shows the comprehensive results of the chemical components of the sludge. The obvious spectroscopy characteristic peaks are characterized by the absorption of typical chemical components of the sludge in the figures, and the characteristic peaks are contributed by the main materials in the sludge cells. Fig. 4 refers to the infrared spectrum before and after sludge leaching; the main absorbance bands and their assignments are listed in Table 2. From the contrastive analysis of Figs 4(a) and 4(b), organic matter in the sludge mainly comprises saccharides, proteins, and aliphatic substances. Similar infrared characteristics are represented before and after the bioleaching of the sludge, thus indicating the occurrence of insignificant changes in the main components of the
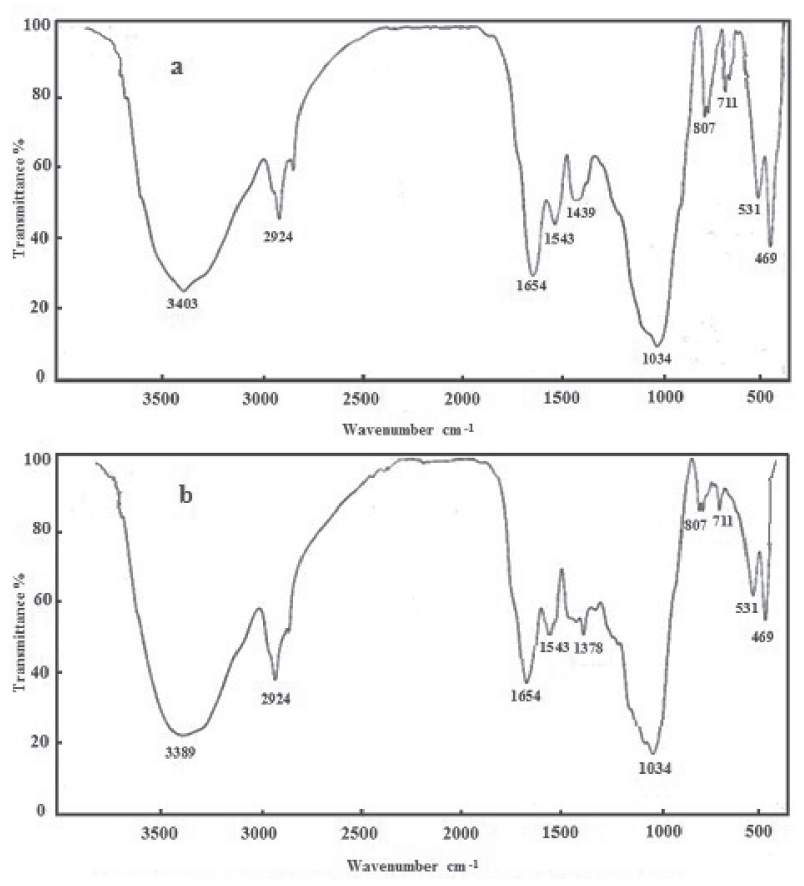

Fig. 4. FTIR of the sludge before and after bioleaching (a) before bioleaching; (b) after bioleaching. sludge before and after bioleaching. Absorption peak strength decreases at $1,654,1,543$, and $711 \mathrm{~cm}^{-1}$ after the bioleaching of the sludge, thus indicating that $A$. niger has taken the effect of degradation on aromatic compounds in the sludge and that the land-use environment security of the sludge improves. The absorption peak disappears at 1,439 $\mathrm{cm}^{-1}$ because of the release of $\mathrm{NH}_{4}^{+}-\mathrm{N}$ and $\mathrm{NO}_{3}^{-}-\mathrm{N}$ in the sludge during bioleaching. The peak strength decreases at 1,034 and $807 \mathrm{~cm}^{-1}$ because the acid generation from $A$. niger forms a low $\mathrm{pH}$ environment that converts organic phosphorus in the sludge into $\mathrm{HPO}_{4}{ }^{2-}$ and $\mathrm{H}_{2} \mathrm{PO}_{4}^{-}$, which exist in the liquid phase, damages the $\mathrm{Si}-\mathrm{O}$ structure in the sludge, and promotes the dissolution of heavy metals in the residual fraction in the sludge. Absorption peak strength significantly decreases at 531 and $469 \mathrm{~cm}^{-1}$, thus indicating damage on the Fe-Mn oxide structure in the sludge. The organic acids generated from $A$. niger can accelerate the dissolution of heavy metals bound to Fe-Mn oxides in the sludge and improve the removal efficiency of heavy metals in the leaching system. A new absorption peak appears at $1,378 \mathrm{~cm}^{-1}$ in the sludge after leaching, and the strength increases at $2924 \mathrm{~cm}^{-1}$. Both changes are related to the increasing aliphatic compounds in the sludge, thus indicating the degradation of aromatic compounds in the sludge into aliphatic compounds under the effect of A. niger. In summary, bioleaching does not result in the evident loss of organic functional groups or the reduction of land-use value in the sludge.

\section{Security Analysis of Sludge Land Use}

Wheat differs from sprouting and growth during $15 \mathrm{~d}$ in the soil sample with different treated sludge amounts. When the sludge amount surpasses $60 \%$, stem leaf over ground shows toxicity symptoms after 10 days of sprouting, and the blade starts to bend downward. Due to nutrient elements like $\mathrm{N}, \mathrm{P}$ and $\mathrm{K}$ in the sludge promote growth of plant root and stem. Fig. 5 shows the increased rate of stem leaf dry weight and root dry weight of wheat after 15 days of sprouting compared with that of control group (without sludge) in the soil sample with different

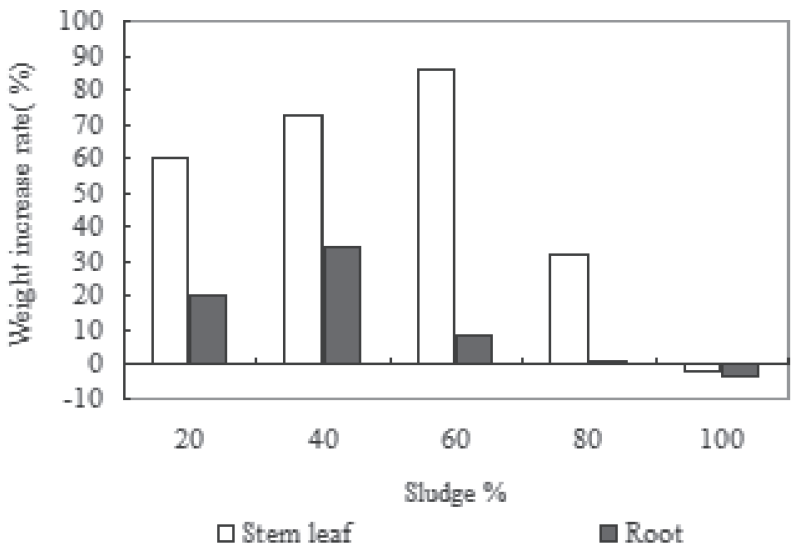

Fig. 5. Varation in apparent characters of wheat with applied treated sludge amount by sprouting test after 15 days. 
treated sludge amounts. Seen from Fig. 5, adding sludge makes a difference in impact on wheat root and stem leaf growth. When the sludge amount is no more than $60 \%$, dry weight of wheat stem leaf increases with increases of sludge amount, and the maximum amplitude is $86 \%$. When the sludge amount is no more than $40 \%$, dry weight of wheat root increases with an increase in sludge amount, and the maximum increase rate is $34 \%$. When the sludge amount is up to $80 \%$, the increased rate of dry weight of root and stem leaf is reduced, which indicates that heavy metal in the sludge restrains from growth of root and stem leaf.

Fig. 6 shows heavy metal accumulation change in wheat root and stem leaf with sludge amount after bioleaching. Seen from Figure 6, with an increase of sludge amount, $\mathrm{Cu}, \mathrm{Zn}, \mathrm{Pb}$ and $\mathrm{Cd}$ accumulation in the root and stem leaf increases and heavy metal accumulation in the wheat root is significantly higher than that in stem leaf, which indicates that the enrichment capacity for heavy metals of the root is stronger than that of stem leaf, so weight increase rate of root is not as significant as that of stem leaf.

Average migration coefficient of $\mathrm{Cu}, \mathrm{Zn}, \mathrm{Pb}$ and $\mathrm{Cd}$ from root to stem leaf is $0.69-0.47$. In contrast, $\mathrm{Cu}$ can be easily migrated to stem leaf over ground and enter the food chain, while $\mathrm{Zn}$ gets poorer migration capacity to stem leaf and less hazard to humans and animals. Enrichment capacity order of different heavy metals is $\mathrm{Zn}>\mathrm{Pb}>\mathrm{Cu}>\mathrm{Cd}$ in wheat root and stem leaf, which is consistent with the conclusion of heavy metal fraction analysis.

Bio-availability and migration order of different heavy metal fractions is acid-soluble/exchangeable fraction $>$ reducible fraction $>$ oxidizable fraction $>$ residual fraction, among which acid-soluble/exchangeable and reducible fraction can also be called unstable fraction. Zn gets the highest unstable fraction content in the sludge after bioleaching, as well as the most significant bio-availability and
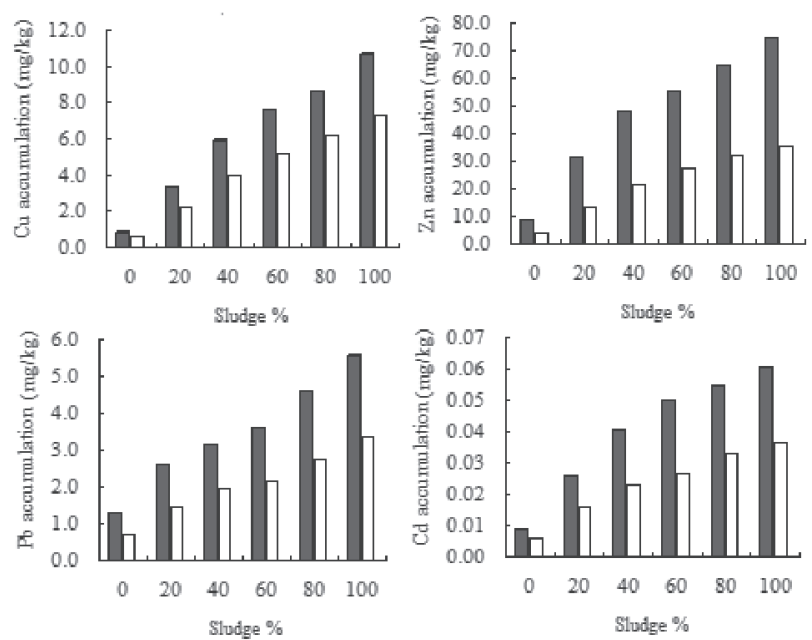

Q Root $\square$ Stem leaf

Fig. 6. Varation in accumulation of heavy metals in root and steam leaf of wheat with the applied sludge amount after bioleaching. migration, so wheat has the strongest enrichment capacity for $\mathrm{Zn}$. The sludge after bioleaching gets the lowest unstable fraction content of $\mathrm{Cd}$ and wheat has the weakest enrichment capacity for $\mathrm{Cd}$. Plant enrichment capacity for heavy metal is different from transshipment capacity of heavy metal in the plant, and such a difference results from different enrichment capacities for heavy metal of different plant parts. Statistical analysis of experimental data indicates a significantly positive correlation between $\mathrm{Cu}, \mathrm{Zn}, \mathrm{Pb}$, and $\mathrm{Cd}$ accumulation in wheat root and stem leaf and unstable fraction content in the sludge after bioleaching with 0.96-0.99 $(P<0.05)$ correlation coefficient.

Although heavy metal content in the sludge is reduced significantly after bioleaching, the sludge still contains a certain amount of unstable heavy metal fraction. $\mathrm{Cu}, \mathrm{Zn}$, and $\mathrm{Cd}$ content in the sludge after bioleaching still surpasses secondary standard in Environmental quality standards for soils (GB15618-1995) under the experimental condition as 3.1, 2.2, and 4.0 times of standard value, respectively (refer to Table 1). A large amount of sludge is applied in the farmland, where heavy metal accumulation in plants can harm human health, so the proportion of applied sludge shall be controlled in farmland use, and the appropriate ratio of sludge and soil is $60 \%$, taking wheat growth and heavy metal residues into consideration under experimental conditions.

\section{Conclusion}

After leaching with $A$. niger, over $95 \%$ and $90 \%$ of $\mathrm{Zn}, \mathrm{Cd}, \mathrm{Cu}$, and $\mathrm{Pb}$ acid-soluble/exchangeable fractions and reducible fractions are removed from the sludge, respectively. Acid-soluble/exchangeable fractions decrease to $1.0 \%$ and $5.4 \%$ in the sludge, whereas residual fractions increase to $52.3 \%$ and $81.7 \%$. After bioleaching, the bioavailability of heavy metals in the sludge greatly decreases. For the sludge in an acidic environment for 12 days during bioleaching, the loss rate of total N, P, and $\mathrm{K}$ are $29.8 \%, 13.3 \%$, and $28.8 \%$ in the sludge, respectively. After the separation of solids and liquids in the leaching system, some nutritive materials in the culture medium and $A$. niger may be adsorbed on particles of the sludge. A. niger is rich in nutritive elements such as $\mathrm{N}, \mathrm{P}$, and $\mathrm{K}$, thus the land-use value in the sludge does not decrease. According to infrared spectroscopy analysis, the FeMn oxide structure in the sludge is damaged to a certain extent. The indirect available fraction is transferred to the available fraction, and the removal efficiency of heavy metals in the leaching system improves. A. niger has taken the effect of degradation on aromatic compounds in the sludge, and the land-use environment security of the sludge improves. Organic matter in the sludge mainly comprises saccharides, proteins, and aliphatic substances. Bioleaching does not result in an evident loss of organic functional groups. Adding the right amount of sludge in soil can significantly increase dry weight of wheat root and stem leaf. With increasing sludge amounts, $\mathrm{Cu}, \mathrm{Zn}$, $\mathrm{Pb}$, and $\mathrm{Cd}$ accumulation in the root and stem leaf is 
increased and heavy metal accumulation in the wheat root is higher significantly than that in stem leaf. Enrichment capacity order of different heavy metals is $\mathrm{Zn}>\mathrm{Pb}>\mathrm{Cu}>\mathrm{Cd}$ in wheat root and stem leaf, which is consistent with the conclusion of heavy metal fraction analysis.

\section{Acknowledgements}

This project was supported by the Project Funded by the Priority Academic Program Development of Jiangsu Higher Education Institutions (PAPD).

\section{References}

1. REN W.X., LI P.J., GENG Y., LI X.J. Biological leaching of heavy metals from a contaminated soil by Aspergillus niger. J. Hazard. Mater. 167 (1-3), 164, 2009.

2. PATHAK A., DASTIDAR M.G., SREEKRISHNAN T.R. Bioleaching of heavy metals from sewage sludge: Areview. J. Environ. Manage. 90 (8), 2343, 2009.

3. BAYAT B., SARI B. Comparative evaluation of microbial and chemical leaching processes for heavy metal removal from dewatered metal plating sludge. J. Hazard. Mater. 174 (1-3), 763, 2010.

4. QU Y., LIAN B., MO B.B, LIU C.Q. Bioleaching of heavy metals from red mud using Aspergillus niger. Hydrometallurgy, 136, 71, 2013.

5. GU X.Y.,WONG J.W. Identification of inhibitory substances affecting bioleaching of heavy metals from anaerobically digested sewage sludge. Environ. Sci. Technol. 38 (10), 2934, 2004.

6. XU T.J., TING Y.P. Fungal bioleaching of incineration fly ash: Metal extraction and modeling growth kinetics. Enzyme and Microbial Technol. 44, 323, 2009.

7. WANG Q.H., YANG J., WANG Q., WU T.J. Effects of water-washing pretreatment on bioleaching of heavy metals from municipal solid waste incinerator fly ash. J. Hazard. Mater. 162 (2-3), 812, 2009.

8. AMIRI F., YAGHMAEI S., MOUSAVI S.M., Sheibani S. Recovery of metals from spent refinery hydrocracking catalyst using adapted Aspergillus niger. Hydrometallurgy, 109 (1-2), 65, 2011.

9. AMIRI F., MOUSAVIC S.M., YAGHMAEI S., BARATI M. Bioleaching kinetics of a spent refinery catalyst using $A s$ pergillus niger at optimal conditions. Biochem. Eng. J., 67, 208, 2012.
10. MOHAPATRA S., PRADHAN N., MOHANTY S., SUKLA L.B. Recovery of nickel from lateritic nickel ore using $A s$ pergillus niger and optimization of parameters. Miner. Eng. 22 (3), 311, 2009.

11. RENOUX A.Y., TYAGI R.D., SAMSON R. Assessment of toxicity reduction after metal removal in bioleached sewage sludge.Water Res. 35 (6), 1415, 2001.

12. MORITA H., TSUBOL H. Basic investigation on the chemical forms of heavy metals in a sewage treatment plant. Water Sci.Technol. 42 (9), 159, 2000.

13. WANG C., LI X.C., MA H.T., QIAN J., ZHAI J.B. Distribution of extractable fractions of heavy metals in sludge during the wastewater treatment process. J. Hazard. Mater. 137 (3), $1277,2006$.

14. JING Q.R.Organic acid production technology, Light Industry Press, Beijing, China. 19, 1989.

15. TSEKOVA K., TODOROVA D., GANEVA S. Removal of heavy metals from industrial wastewater by free and immobilized cells of Aspergillus niger. Int. Biodeterior. Biodegrad. 64 (6), 447, 2010.

16. HE M.M., YU Y.T., HUA Y.M., ZHOU G.D., XU J., TIAN G.M. Removal of heavy metals in sewage sludge and losses of nutrition during bioleaching. J. Agro-Environ. Sci. 25 (5), 1359, 2006

17. HUA Y.M., CHEN Y.X., WU W.X., TIAN G.M. Feasibility of bioleached sewage sludge in land application. Chinese J. Ecology. 26 (8), 1204, 2007.

18. WONG J.W.C., XIANG L., CHAN L.C. pH requirement for the bioleaching of heavy metals from anaerobically digested wastewater sludge. Water, Air, Soil Pollut. 1389 (1-4), 25, 2002.

19. RAJAE A., GHITA A.B., SALAH S., PETER W., JUAN C., MOHAMED H. Aerobic biodegradation of sludge from the effluent of a vegetable oil processing plant mixed with household waste: Physical-chemical, microbiological, and spectroscopic analysis. Bioresour. Technol. 99 (18), 8571, 2008.

20. ABOUELWAFA R., AMIR S., SOUABI S., WINTERTON P., NDIRA V., REVEL J.C., HAFIDI M. The fulvic acid fraction as it changes in the mature phase of vegetable oil-mill sludge and domestic waste composting. Bioresour. Technol. 99 (14), 6112, 2008.

21. WENG S.F. Analysis of fourier Transform infrared spectroscopy, Second Edition, Chemical Industry Press, Beijing, China. 291, 2010.

22. SOUMIA A., ABDELMAJID J., ABDELILAH M., MOHAMED E. G., PETER W., MOHAMED H. Structural study of humic acids during composting of activated sludge-green waste: Elemental analysis, FTIR and ${ }^{13} \mathrm{C}$ NMR. J. Hazard. Mater. 177 (1-3), 524, 2010. 